\title{
Association of Vitamin D Deficiency And Respiratory Syncytial Virus With Severe Lower Respiratory Tract Infection In Newborn Intensive Care Unit
}

\section{Sinan Tüfekci}

Namik Kemal Universitesi Tip Fakultesi

Erhan Aygün ( $\nabla$ dr.erhanaygun@gmail.com)

Istanbul Universitesi Istanbul Tip Fakultesi https://orcid.org/0000-0002-4495-5824

\section{Research}

Keywords: Vitamın D Deficiency, Respiratory Syncytial Virus

Posted Date: August 24th, 2020

DOI: https://doi.org/10.21203/rs.3.rs-59434/v1

License: (c) (1) This work is licensed under a Creative Commons Attribution 4.0 International License.

Read Full License 


\section{Abstract}

Background: Newborn infants are exposed to life-threatening conditions such as severe lower respiratory tract infections mostly caused by a respiratory syncytial virus. Previous studies suggest vitamin D deficiency is associated with an increased risk of lower respiratory tract infections but this hypothesis is controversial. This study aimed to assess the relationship between serum vitamin D levels and the occurrence of lower respiratory tract infections among Turkish infants.

Methods: We performed a case-control study including newborns admitted in the neonatal intensive care unit. Respiratory syncytial virus related respiratory infections were confirmed by the Respi-strip test. Clinical and biological data were collected from medical records and analyzed with Epi Info7.

Results: We included 18 newborns (9 cases with the diagnosis of respiratory syncytial virus-related lower respiratory tract infections and 9 controls admitted with another diagnosis). Their mean age was 23.72 days and sex-ratio was 2 . The main clinical symptoms of lower respiratory tract infections were cough, tachypnea, and fever and respiratory syncytial virus test was positive in all cases. Vitamin D level was significantly lower in cases compared to the control group (5.40 vs $17.67 \mathrm{ng} / \mathrm{ml}$ respectively). All newborns with lower respiratory tract infections presented vitamin D deficiency and $11.1 \%$ of controls had normal vitamin D status. All babies and mothers with vitamin D deficiency were supplemented.

Conclusion: Our results suggest that severe lower respiratory tract infections is associated with lower vitamin D levels among newborns admitted in neonatal intensive care unit. Vitamin D supplementation could help correct this deficiency and prevent postnatal severe lower respiratory tract infections.

\section{Background}

Each year 1.5 million children under the age of 5 years die from pneumonia and respiratory syncytial virus (RSV) is the number one cause of bronchiolitis and pneumonia in children under 1 year of age $[1,2]$.

The preterm newborn is at high risk of developing life-threatening RSV respiratory infections [2]. Immaturity of the immune system in premature and very young infants and the smaller caliber of their airways are both thought to contribute to their susceptibility to severe lower respiratory tract infection (LRTI) $[3,4]$.

Vitamin D plays an important role during neonatal period through direct effects on newborn immune system. Its receptors are widely expressed amongst cells of the innate and adaptive immune system, including dendritic cells and macrophages. When stimulated, these cells produce human cathelicidin protein (HCAP-18), which augments the microbial killing capacity of phagocytes and activates anaphylactoid factors that promote neutrophil and monocyte migration to the site of infection [5]. In addition, vitamin $\mathrm{D}$ also suppresses the release of pro-inflammatory cytokines and chemokines such as 
IL-1 $\beta$, IL-6, IL-8, and TNF-a [6]. Thus vitamin D deficiency has been hypothesized to be a culprit in the risk and severity of acute LRTI in both adults and children. However, in the literature, there are few studies examining the relationship between vitamin D levels and LRTI-associated sepsis in newborns and without clinical signs of rickets. This study aimed to assess relationship between serum vitamin $\mathrm{D}$ level and the occurrence of LRTI among Turkish infants.

\section{Material And Methods}

This retrospective study was conducted in neonatal intensive care unit. The research procedure was approved by the ethical committe (Report number: 2019.143.09.03). In a case-control study, we included nine infants admitted in neonatal intensive care unit (NICU) between in 2018-2019 with the diagnosis of RSV-related severe LRTI and nine controls who presented similar characteristics but without respiratory diseases.

Diagnosis of neonatal severe LRTI was defined as presence of clinical symptoms of pulmonary infections, suggestive radiological findings and identification of RSV antigen in the nasopharyngeal swab samples using the RSV Respi-strip test kit (CorisR). For each baby after seeking free consent of parents, we collected sociodemographical and clinical parameters including age, gender, physical examination, and clinical findings, biological and radiological findings, treatment used and mothers' characteristics. According to their serum $25-\mathrm{OH}$ vitamin $\mathrm{D}$ levels, newborns were classified as having normal vitamin $\mathrm{D}$ status ( $>30 \mathrm{ng} / \mathrm{ml})$, vitamin D deficiency (between $20-30 \mathrm{ng} / \mathrm{ml})$ or carency $(<20 \mathrm{ng} / \mathrm{ml})$ [7].

Statistical analyses were performed using SPSS Statistics version 15.0 (IBM). Descriptive statistics were reported as percent, mean \pm standard deviation, median, and ranges (min-max) as appropriated. To compare clinical and biological parameters between cases and controls, we used Fisher exact test, Mann Whitney $\mathrm{U}$ and Khi-square tests as appropriate. The relationship between two sets of data was analyzed by Spearman's rank correlation test. All comparative tests were 2-tailed and $p \leq 0.05$ was considered as significant.

\section{Results}

Mean age of the 18 patients included in the study was $23.72 \mathrm{~d}$ and only $33 \%$ were female. The anthropometrical and clinical characteristics were comparable between newborns in the case and the control groups (table I).

Table I Newborns' charateristics 


\begin{tabular}{|l|l|l|c|}
\hline Parameters & Cases & Controls & p-value \\
\hline Age (days) & $23.11 \pm 09.09$ & $24.33 \pm 01.32$ & 0.33 \\
\hline Term of birth & $38.22 \pm 02.44$ & $38.11 \pm 01.90$ & 0.69 \\
\hline Weight (g) & $2706.67 \pm 360$ & $2811.11 \pm 357$ & 0.48 \\
\hline Length (cm) & $46.78 \pm 01.86$ & $48.72 \pm 02.14$ & 0.08 \\
\hline Skull circonference $(\mathrm{cm})$ & $32.83 \pm 01.12$ & $34.11 \pm 01.02$ & 0.04 \\
\hline Calcemia (mg/l) & $09.14 \pm 0.54$ & $09.34 \pm 0.52$ & 0.33 \\
\hline Phosphoremia $(\mathrm{mg} / \mathrm{l})$ & $06.14 \pm 0.49$ & $06.39 \pm 0.72$ & 0.49 \\
\hline 25-OH Vitamin D level (ng/ml) & $05.40 \pm 01.94$ & $17.67 \pm 05.54$ & $<0.01$ \\
\hline
\end{tabular}

The duration of prodromal symptoms was between 1-4 days before admission. In addition to symptoms of upper respiratory infection, cough, wheezing, tachypnea, decreased suctioning, fever, apnea (two cases), hypotonia (two cases) were present. As a source of transmission, there were signs of upper respiratory tract infection in the parents/siblings. The duration of gestational period ranged from 33 to 41 weeks. Two babies were born with low birth weight and two others were born prematurely. All cases were fed with breast milk, and two infants were given supplementation with formula in addition to breast milk. Only 5 babies had passive smoking exposure among the newborns with LRTI. All newborns with LRTI presented vitamin D deficiency and $11.1 \%$ of controls had normal vitamin D status (Fig. 1). Median serum $25-\mathrm{OH}$ vitamin D level was significantly lower in newborns with severe LRTI than in controls $(6.4 \mathrm{ng} / \mathrm{ml}$ and $18.3 \mathrm{ng} / \mathrm{ml}$ respectively in cases and controls, $p<0.01)$. Table II presents the mothers' characteristics. Median vitamin D level was $7.6 \mathrm{ng} / \mathrm{ml}(3.8-14.6)$ in mothers of cases and $21.5 \mathrm{ng} / \mathrm{ml}(9.9-30.1)$ for the controls' mothers. There was a significant correlation between newborn's serum vitamin $D$ level and the mother's one among case and control gs (cases: $r=0.88, p=<0.01$, controls: $r=0.77 p=0.02$ ). All newborns had normal calcium, phosphorus, and alkaline phosphatase levels. However, any mother did not receive adequate vitamin D supplementation during pregnancy. However, babies with vitamin $D$ deficiency and their mothers were given vitamin $\mathrm{D}$ at the treatment dose. Two patients had Staphylococcus epidermidis in blood culture and one patient had Enterobacter cloaca in tracheal aspirate culture. Interstitial infiltration was detected on chest radiographs of patients with LRTI due to RSV. Echocardiography revealed secundum atrial septal defect (ASD) in two patients and patent foramen ovale (PFO) in one patient. All RSV antigen-positive infants were hospitalized in an isolated room. For the management of patients with LRTI, mechanical ventilation support, oxygen, TPN, iv fluid, antibiotic and $\beta 2$-agonists were used. Two patients required advanced mechanical ventilation with High-Frequency Ventilation (HFO). Four patients required intubated mechanical ventilation during 3 to 11 days. This duration was inversely correlated to vitamin $D$ level $(r=-0.65 ; p=0.02)$. Nine patients required nasal CPAP and total parenteral nutrition support was given to seven babies. 
Table II Mothers' characteristics

\begin{tabular}{|c|c|c|c|}
\hline Parameters & Mothers of cases & Mothers of controls & p-value \\
\hline Age (years) & $30.89 \pm 06.77$ & $27.56 \pm 05.43$ & 0.33 \\
\hline $\begin{array}{r}\text { Education level } \\
\text { primary school } \\
\text { hiddle school school } \\
\text { uneducated }\end{array}$ & $\begin{array}{l}22.22 \% \\
22.22 \%\end{array}$ & $\begin{array}{l}33.33 \% \\
22.22 \% \\
22.22 \%\end{array}$ & 1.00 \\
\hline Number of pregnancy & $02.22 \pm 0.97$ & $02,33 \pm 1,00$ & 0.78 \\
\hline Number of attended prenatal visits & $02.22 \pm 0,97$ & $02,33 \pm 1,00$ & 0.78 \\
\hline Level of exposition to smoking & $55.55 \%$ & $33.33 \%$ & 0.56 \\
\hline Calcemia (mg/l) & $09.30 \pm 0.41$ & $09.67 \pm 0.48$ & 0.08 \\
\hline Phosphatemia (mg/l) & $06.36 \pm 0.49$ & $06.28 \pm 0.44$ & 0.93 \\
\hline 25-OH Vitamin D level (ng/ml) & $07.61 \pm 3.68$ & $20.31 \pm 7.32$ & $<0.01$ \\
\hline
\end{tabular}

\section{Discussion}

Vitamin D plays a key role in bone metabolism through regulation of calcium and phosphate homeostasis since early life and may also play an important role in immune system regulation. Previous studies had demonstrated association between, 25-OH vitamin D level in cord blood and subsequent risk of developing respiratory infection in infants [7-9]. However, other authors did not find any relationship between vitamin D and LRTI among newborns [4]. In this study, serum 25-OH vitamin D was lower in infants with severe RSV-related LRTI and their mothers. Even though newborns and mothers in the control group had vitamin D deficiency, their serum levels were slightly higher. Also, Beigelman et al. [4] reported a high rate of vitamin D deficiency in infants and mothers with LRTI.

The high prevalence of vitamin D deficiency in our patients was attributed to lack of vitamin D supplementation during pregnancy, the dressing habits of Turkish women and low exposure to sunlight during winter season. Vitamin $D$ deficiency can hamper its immunomodulatory effects through direct effect on cell proliferation, differentiation and apoptosis of T lymphocytes and B lymphocytes [10]. Randolph et al. [11] found that children hospitalized with RSV-related bronchiolitis were more likely to carry the GC1s haplotype, which is associated with higher levels of vitamin D binding protein, and lower available 25-OH vitamin D. This may explain the high incidence of infection in our cases group where all participants had low serum vitamin D level. 
Furthermore, a strong inverse correlation was found between the intubation time and vitamin $D$ level of newborns in the case group. Similarly, Fairchok et al. [12] found that babies with vitamin D insufficiency had a significantly longer duration of hospitalization and also required more oxygen support. The World Health Organization recommends vitamin D supplementation because to help reducing incidence and severity of acute LTRI, as well as all-cause mortality in newborns particularly in populations with low exposure to sunlight $[13,14]$. Camargo et al. [15] reported that the frequency of wheezing decreased in asthmatic infants of whose mothers received vitamin $D$ supplementation during pregnancy and during the first 3 years of life.

\section{Conclusion}

Our results suggest that severe LRTI is associated with lower vitamin D levels among newborns admitted in NICU. Therefore correction of vitamin D deficiency with supplementation might have a significant impact on prevention and treatment of postnatal life threatening respiratory infections in newborns. Further interventional studies in larger samples are needed to confirm the efficacy and efficiency of such a strategy.

\section{Abbreviations}

LRTI: Lower respiratory tract infections

NICU: Neonatal intensive care unit (NICU)

RSV: Respiratory syncytial virus

\section{Declarations}

Ethics approval and consent to participate: The research procedure was approved by the ethical committe (Report number: 2019.143.09.03).

\section{Consent for publication}

Not applicable.

\section{Availability of data and materials}

Availability of data and material at Tekirdağ Namık Kemal University Hospital

\section{Competing interests}

The authors declared no conflicts of interest with respect to the authorship and/or publication of this article.

\section{Funding}


The authors received no financial support for the research and/or authorship of this article.

\section{Authors' contributions}

ST planned the study, ST and EA collected the data, ST and EA performed the statistical analysis, ST and EA analyzed the literature, EA was a major contributor in writing the manuscript study. Two authors read and approved the final manuscript.

\section{Acknowledgements}

Not applicable.

\section{References}

1. Stockman LJ, Curns AT, Anderson LJ, Fischer-Langley G. Respiratory syncytial virus associated hospitalizations among infants and young children in the United States, 1997-2006. Pediatr Infect Dis J 2012; 31(1):5-9.

2. Hall CB. Respiratory syncytial virus and parainfluenza virus. N Engl J Med 2001; 344:1917-28.

3. Laprecht CL, Krause HE, Mufson MA. Role of maternal antibody in pneumonia and bronhiolitis due to respiratory syncytial virus. J İnfect Dis 1976; 134:211-217

4. Beigelman $A$, Catro $M$, Schweiger $T L$, et al. Vitamin $D$ levels are unrelated to the severity of respiratory syncytial virus bronchiolitis among hospitalized infants. J Pediatric Infect Dis Soc 2015; 4:182-188.

5. Di Rosa M, Malaguarnera M, Nicoletti F, Malaguarnera L. Vitamin D3: a helpful immunomodulator. Immunology 2011; 134:123-139.

6. Gombart AF, Borregaard N, Koeffler HP. Human cathelicidin antimicrobial peptide (CAMP) gene is a direct target of the vitamin $D$ receptor and is strongly up-regulated in myeloid cells by $1,25-$ dihydroxyvitamin D3. FASEB J 2005; 19: 106.

7. Bahn I, Camargo CA, Wenger J, et al. Circulating levels of 25 -hydroxyvitamin D and cathelicidin levels in healthy adults. J All Clin Immunol 2011; 127:1302-1304.

8. Maxwell CS, Carbone ET, Wood RJ. Better newborn vitamin D status lowers RSV-associated bronchiolitis in infants. Nutr Rev 2012; 70(9):548-52.

9. Morales E, Romieu I, Guerra S, et al. Maternal vitamin D status in pregnancy and risk of lower respiratory tract infections, wheezing, and asthma in offspring. Epidemiol Camb Mass 2012; 23: 6471.

10. Radovic J, Markovic D, Velickov A, Dordevic B, Sojnev S. Vitamin D immunomodulatory effect. Acta Medica Medianae 2012; 51(4):58-63.

11. Randolph AG, Yip WK, Falkenstein-Hagander K, et al. Vitamin Dbinding protein haplotype is associated with hospitalization for RSV bronchiolitis. Clin Exp Allergy 2014; 44:231-237.

12. Fairchok M, Schofield C, Chen WJ. Inverse Correlation between 25-OH Vitamin D Levels and Severity of Viral Respiratory Illness in Infants. J Infect Dis Epidemiol 2017; 3:030. 
13. Manaseki-Holland S, Quader G, Isaq Masher M, et al. Effects of vitamin D supplementation to children diagnosed with pneumonia in Kabul: a randomised controlled trial. Trop Med Intern Health 2010, 15(10):1148-55.

14. Grant CC1, Wall CR, Gibbons MJ, Morton SM, Santosham M, Black RE. Child nutrition and lower respiratory tract disease burden in New Zealand: a global context for a national perspective. $J$ Paediatr Child Health 2011; 47(8):497-504.

15. Camargo Jr CA, Ingham T, Wickens $\mathrm{K}$, et al. Cord blood 25-hydroxyyvitamin D levels and risk of respiratory infection, wheezing, and asthma. Pediatrics 2011; 127(1):180-187.

\section{Figures}

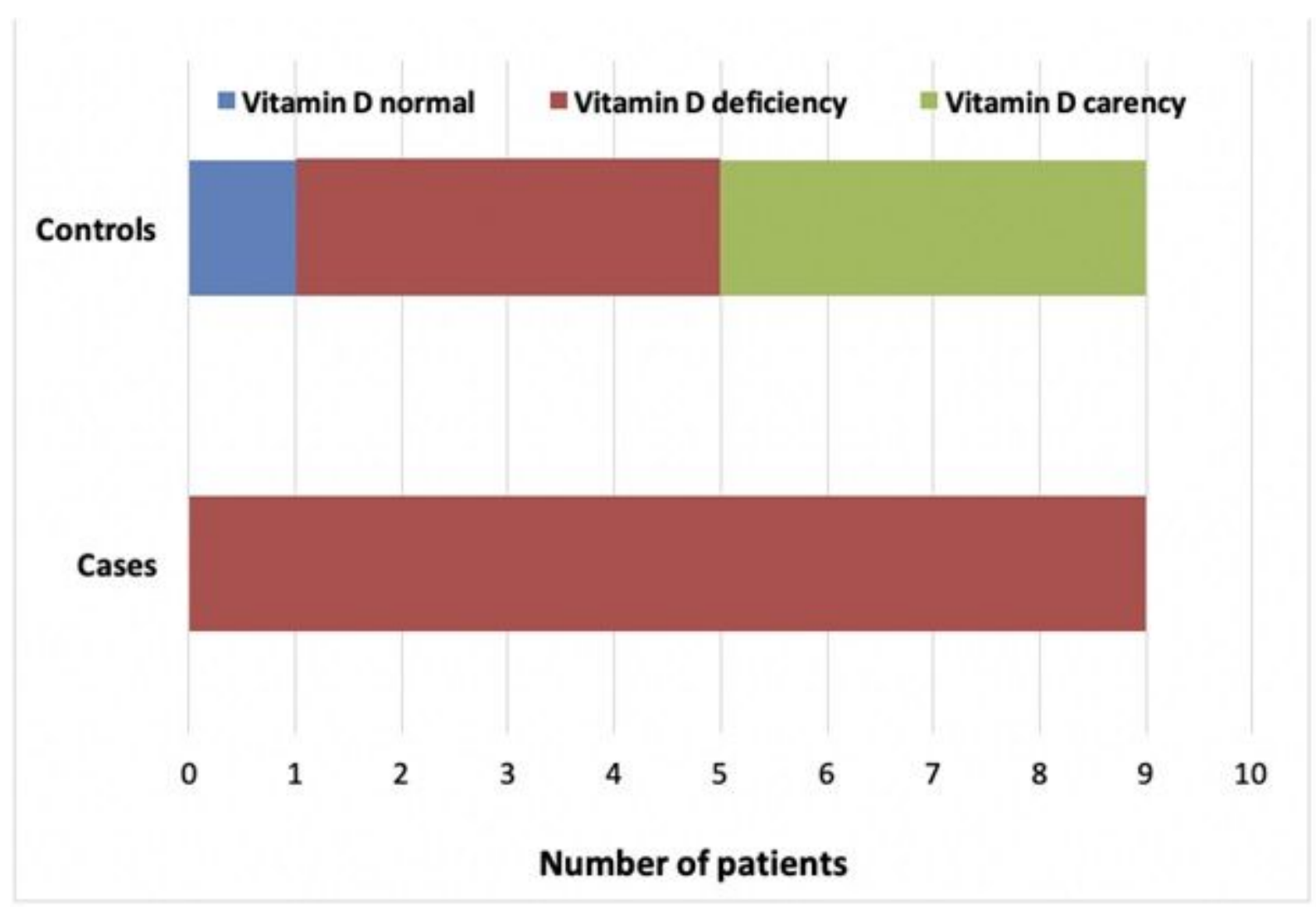

\section{Figure 1}

Vitamin D status in newborns with and without low respiratory tract infection 